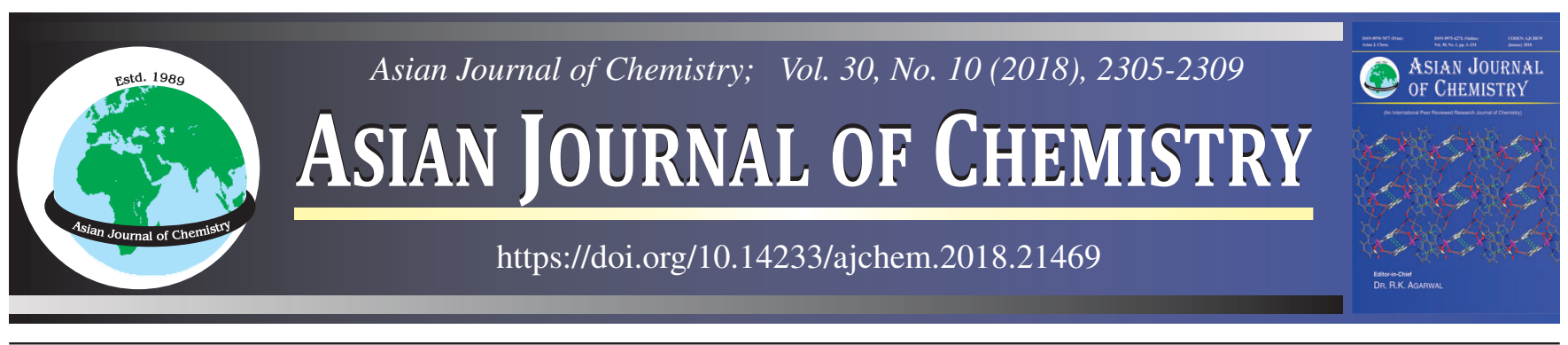

\title{
Silver Nanoparticles Stabilized in Polymeric Resin: Synthesis, Characterization and Catalytic Activity Study for Reduction of $p$-Nitrophenol
}

\author{
Jaya T. VARKeY ${ }^{1, *}$, AnItTA AntonY $^{2}$ and P.A. AjIL ${ }^{2}$
}

${ }^{1}$ Department of Chemistry, St. Teresa's College, Ernakulam-682 035, India

${ }^{2}$ Department of Chemistry, St. Albert's College, Ernakulam-682 018, India

*Corresponding author: E-mail: jayavarkey@yahoo.com

Received: 22 May 2018;

Accepted: 19 July 2018;

Published online: 31 August 2018;

AJC-19063

| A facile method is reported to synthesize a stable dispersion of silver nanoparticles in polymeric resin and its catalytic activity studies. The average particle size of silver nanoparticles obtained was $30 \mathrm{~nm}$. CHNS analysis, FTIR spectra SEM, EDX, TEM, UV-visible spectra were the various techniques used for characterization. Catalytic reduction of $p$-nitrophenol using the synthesized catalyst was the model reaction selected here. The efficiency of catalytic reduction was found to be $93 \%$ in a total time of $24 \mathrm{~min}$.

Keywords: Silver nanoparticles, Reduction, $p$-Nitrophenol.

ᄂ

\section{INTRODUCTION}

The properties of nanoparticles are different from those of bulk metal due to their small size [1]. These novel properties may find application in various fields such as photoelectronics, catalysis, magnetism and sensing [2-8]. Major problem with the synthesis of nanoparticles is their stabilization. Polymers are found to be efficient support for stabilization of nanoparticles. Polymer embedding represents the simplest way to protect the nanoparticles and providing a means of stabilization in handling and applications [9]. In heterogeneous catalysis, styrene-divinyl benzene (PS-DVB) copolymer is most commonly used as supporting system. Due to hydrophobic and rigid nature of polymer backbone, PS-DVB systems show low metal ion uptake.

1,6-Hexanediol diacrylate (HDODA) cross-linked polystyrene (PS-HDODA) possess optimum hydrophobic hydrophilic balance and is more flexible than PS-DVB system [10]. Thus, PS-HDODA has been introduced to be more convenient as catalyst support than PS-DVB system. The challenges in the application of nanoparticles could be overcome by incorporation into hydrogels [11]. Such polymer supported catalyst systems can separate from the products by means of simple filtration which leads to operational flexibility [12]. Immobilized metal nanoparticles find application in several fields such as water treatment, food processing, catalysis, etc. [13]. Silver nanoparticles stabilized in sulphonated cross-linked polystyrene were obtained by in situ reduction of silver nitrate in hydrogel network. Hydrogel network is a carrier where in situ reduction of $\mathrm{AgNO}_{3}$ in the presence of $\mathrm{NaBH}_{4}$ as reducing agent occurred.

$p$-Nitrophenol is a toxic pollutant which causes harmful effects in living organisms [14]. These are widely used in the manufacturing of pesticides, insecticides, fungicides, and also used in the pharmaceuticals and synthetic dye industry [15]. Human exposure to $p$-nitrophenol takes place by inhalation, ingestion and dermal contact. Harmful effects of $p$-nitrophenol on health depends on duration, exposure dose, pathways and individual characteristic such as gender, nutritional status, life style etc. Short-term exposure of $p$-nitrophenol by inhalation or ingestion causes headache, drowsiness, nausea, cyanosis and eye irritation [16]. One of the most toxic derivative of parathion insecticide is $p$-nitrophenol and it is carcinogenic and cytotoxic [17]. It is highly soluble in water bodies such as fresh water, marine environments and in industrial wastewater. Thus traditional water purification methods for the removal of $p$-nitrophenol from waste water are not effective. There are many methods for the removal of $p$-nitrophenol which includes catalytic reduction by using microwaves, microbial degradation, photo-

This is an open access journal, and articles are distributed under the terms of the Creative Commons Attribution-NonCommercial 4.0 International (CC BY-NC 4.0) License, which allows others to copy and redistribute the material in any medium or format, remix, transform, and build upon the material, as long as appropriate credit is given and the new creations are licensed under the identical terms. 
catalytic degradation, electro-fenton method, electro-coagulation and electro-chemical treatment [18-24]. Silver nanoparticles are widely used due to its size, shape and antibacterial properties. Herein, we report the catalytic reduction of $p$-nitrophenol using silver nanoparticles stabilized in polymeric 1,6-hexanediol diacrylate (HDODA) cross-linked polystyrene (PS-HDODA) resin.

\section{EXPERIMENTAL}

Styrene and 1,6-hexanediol diacrylate (HDODA) were purchased form Sigma Aldrich Company. Acetone, methanol, toluene, dimethyl formamide, dichloromethane, benzoyl peroxide, poly(vinyl alcohol), sulphuric acid and silver nitrate were obtained from Merck chemical company. The FTIR spectra were recorded on a Bruker IFS-55 spectrometer using KBr pellets. The scanning electron micrographs were taken using a Hitachi S-2400 instrument. The surface morphology of cross-linked polystyrene and sulphonated polystyrene were studied using SEM and TEM. The UV-visible spectra were recorded on a Shimadzu 160-A spectrometer. EDX image was obtained from EDX 800 Simadzu, Japan instrument. CHNS analysis was done by PerkinElmer 2400 Series CHNS analyzer.

Copolymerization: Cross-linked polystyrene is synthesized by free radical suspension polymerization. For the synthesis of $2 \%$ HDODA cross-linked polystyrene, a mixture of styrene ( $98 \mathrm{mmol}$ ), HDODA ( $2 \mathrm{mmol}$ ), toluene $(8 \mathrm{~mL}$ ) and benzoyl peroxide ( $1 \mathrm{~g}$ ) was prepared. Poly(vinyl alcohol) (1\%) solution is used as suspension medium. The above mixture is mechanically stirred at $80^{\circ} \mathrm{C}$ for $6 \mathrm{~h}$. The product was collected by filtration and then washed with hot water, acetone and methanol and dried at $80^{\circ} \mathrm{C}$.

Sulphonation: The copolymer was swelled in dichloromethane for $0.5 \mathrm{~h}$. Conc. sulphuric acid was added and heated to $50^{\circ} \mathrm{C}$ with periodic shaking, which is needed during sulphonation. The sulphonated resin was filtered, washed with distilled water and dried at $50^{\circ} \mathrm{C}$ for $6 \mathrm{~h} \mathrm{[24]}$ (Scheme-I).
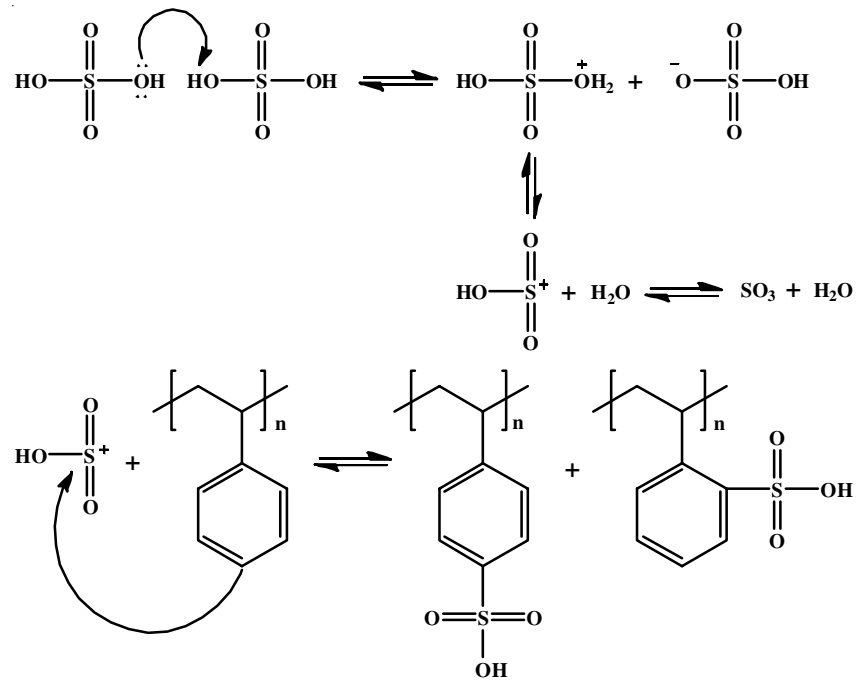

Scheme-I: Sulphonation reaction [Ref. 24]

Ion-exchange capacity: Salt splitting titration is used for the determination of ion-exchange capacity of sulphonated resin. An accurate amount of sulphonated resin was weighed and added into an Erlenmeyer flask containing $2 \mathrm{~N} \mathrm{NaCl}$ solutions. It was stirred for $3 \mathrm{~h}$ and then titrated with standardized $\mathrm{NaOH}$ solution using phenolphthalein as indicator. The ion-exchange capacity of sulphonated resin (IEC, meq/g) was calculated from the following equation:

$$
\text { IEC }=\mathrm{c} \times \mathrm{v} / \mathrm{w}
$$

where $\mathrm{c}$ is the standardized concentration of $\mathrm{NaOH}, \mathrm{v}$ is the volume $(\mathrm{mL})$ of $\mathrm{NaOH}$ solution at end point and $\mathrm{w}$ is the weight (g) of determined sulphonated resin.

Metal loading to polymeric support: The polymeric ligand was equilibrated with $\mathrm{AgNO}_{3}$ solution $(0.05 \mathrm{M} 100 \mathrm{~mL})$ at room temperature for $24 \mathrm{~h}$. The metal loaded polymer was filtered, washed with water and dried under vacuum.

Synthesis of polymer supported metal nanoparticles: Metal ion loaded to polymer supported ( $1 \mathrm{~g}$ ) was suspended in methanol $(10 \mathrm{~mL})$ taken in a round bottom flask and sodium borohydride $(1 \mathrm{~mL}, 20 \mathrm{mmol})$ was added. The reaction mixture was stirred at room temperature for $2 \mathrm{~h}$ to ensure complete reduction. It was filtered under vacuum, washed with methanol $(20 \mathrm{~mL} \times 5)$ and dried under vacuum for $24 \mathrm{~h}$.

Catalytic activity: For water purification from contaminants catalytic approach plays an important role. Here reduction of $p$-nitrophenol using silver nanoparticles stabilized in sulphonated PS-HDODA resin was selected as a model reaction. $\mathrm{NaBH}_{4}$ was used as reducing agent. After catalysis, catalyst can be separated by simple filtration. The percentage catalytic efficiency was calculated.

\section{RESULTS AND DISCUSSION}

A polymeric 1,6-hexanediol diacrylate (HDODA) crosslinked polystyrene (PS-HDODA) hydrogel were synthesised by suspension polymerization and functionalized by sulphonation using conc. $\mathrm{H}_{2} \mathrm{SO}_{4}$, and the ion-exchange capacity of obtained resins were determined by salt splitting titration. Metal ion is loaded to the polymeric support by equilibrating the polymeric ligand with metal salt solution. The metal loaded to polymeric support was reduced into the nano-scale by sodium borohydride. Sulphonated resin showed swelling in polar solvents indicated the presence of hydrophilic group in polymeric system.

CHNS analyses (Table-1) gave sulphur content of 6.27\% indicated the attachment of sulphur containing group. The PSHDODA copolymer resin showed no ion-exchange capacity due to the absence of sulphonic acid group. The sulphonated copolymer showed an ion-exchange capacity of $3.50 \mathrm{meq} / \mathrm{g}$ (Table-2).

\begin{tabular}{lccc}
\multicolumn{5}{c}{ TABLE-1 } \\
\multicolumn{4}{|c}{ CHNS ANALYSIS OF SULPHONATED PS-HDODA } \\
\hline $\mathrm{C}(\%)$ & $\mathrm{H}(\%)$ & $\mathrm{N}(\%)$ & $\mathrm{S}(\%)$ \\
\hline 56.11 & 8.14 & Not detected & 6.27 \\
\hline
\end{tabular}

In FTIR spectra (Figs. 1-3), the resins exhibited a band around 1724-1720 $\mathrm{cm}^{-1}$ indicating carbonyl stretching frequency, which is an indication HDODA cross-linking to the polymeric support system. Bands at 1657-1598, 1493-1473 and 1451$1443 \mathrm{~cm}^{-1}$ corresponds to phenyl ring stretching vibrations of $\mathrm{C}=\mathrm{C}-\mathrm{C}$ conjugative system. The frequency in the range 1166 


\begin{tabular}{|c|c|c|c|c|}
\hline \multicolumn{5}{|c|}{$\begin{array}{c}\text { TABLE } 2 \\
\text { ION-EXCHANGE CAPACITY OF SULPHONATED RESIN }\end{array}$} \\
\hline Sample name & $\begin{array}{l}\text { Sulphonating } \\
\text { time (min) }\end{array}$ & $\begin{array}{c}\text { Volume of sulphuric } \\
\text { acid (mL) }\end{array}$ & Temperature $\left({ }^{\circ} \mathrm{C}\right)$ & $\begin{array}{l}\text { Ion exchange capacity } \\
\text { (IEC) }(\mathrm{meq} / \mathrm{g})\end{array}$ \\
\hline PS-HDODA resin & - & - & - & 0.00 \\
\hline PS-HDODA SO $\mathrm{SO}_{3} \mathrm{H}$ & 40 & 2 & 60 & 3.50 \\
\hline
\end{tabular}

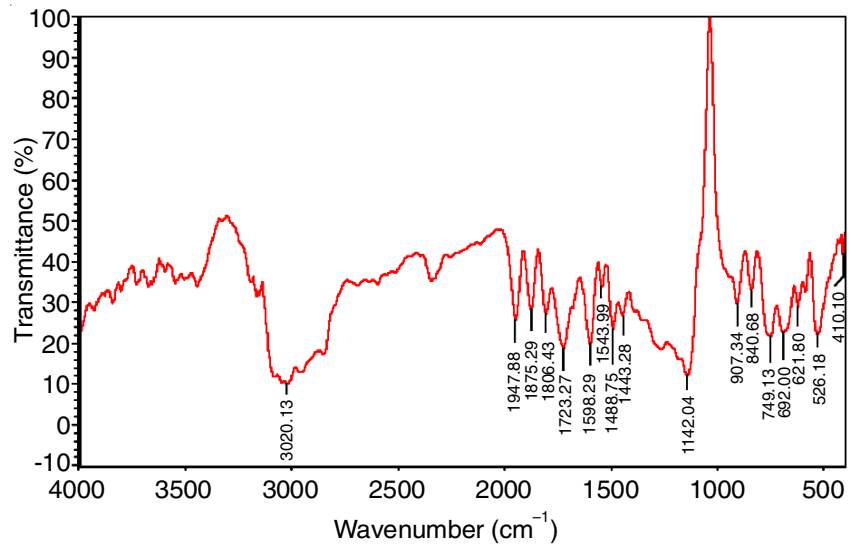

Fig. 1. FTIR spectra of PS-HDODA resin

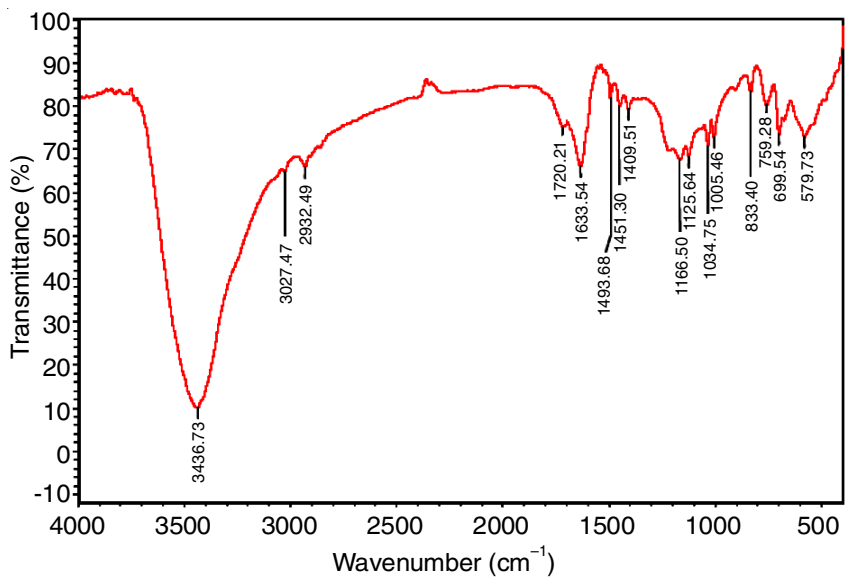

Fig. 2. FTIR spectra of sulphonated PS-HDODA resin

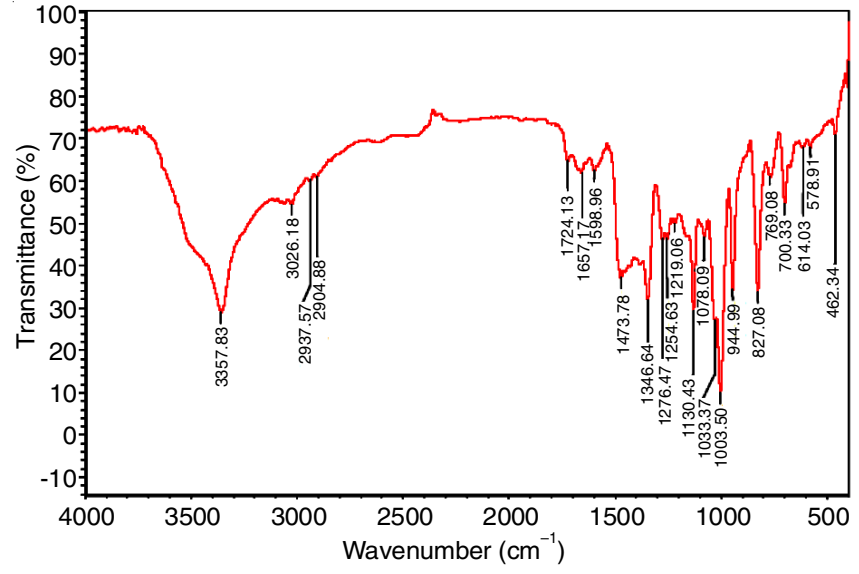

Fig. 3. FTIR spectra of silver nanoparticles loaded sulphonated PS-HDODA resin

$\mathrm{cm}^{-1}$ was attributed to $\mathrm{S}=\mathrm{O}$ symmetric stretching vibration. On silver metal nanoparticles loaded, the $\mathrm{S}=\mathrm{O}$ stretching frequency lowered to $1130 \mathrm{~cm}^{-1}$ while the bands at 1078-1033 and $907 \mathrm{~cm}^{-1}$ represented phenyl in-plane and out of plane $\mathrm{C}-\mathrm{H}$ bending vibrations, respectively. Moreover, the band at 759$700 \mathrm{~cm}^{-1}$ phenyl ring wagging and twisting, respectively (Table-3).

Scanning electron microscopy is used for surface morphological analysis of polymeric resin. All copolymer resin retained spherical morphology. PS-HDODA copolymer resin have very smooth surface. But the external surface of sulphonated copolymer resin showed scales and cracks probably by sulphonation process. When silver nanoparticles loaded, the external surface of polymeric resin became more and more rough (Fig. 4).

\begin{tabular}{lcccc}
\multicolumn{5}{c}{ TABLE-3 } \\
KEY BAND $\left(\mathrm{cm}^{-1}\right)$ OF SILVER NANOPARTICLES STABILIZED IN POLYMERIC RESIN \\
\hline \multicolumn{1}{c}{ System } & $v(-\mathrm{C}=\mathrm{O})$ & $v(-\mathrm{S}=\mathrm{O})$ & $v(-\mathrm{OH})$ & $v(=\mathrm{C}-\mathrm{H})$ \\
\hline PS-HDODA resin & & 1723 & - & - \\
Sulphonated PS-HDODA resin & 1720 & 1166 & 3436 & 3020 \\
Silver nanoparticles loaded sulphonated PS-HDODA resin & 1724 & 1130 & 3357 & 3027 \\
\hline
\end{tabular}
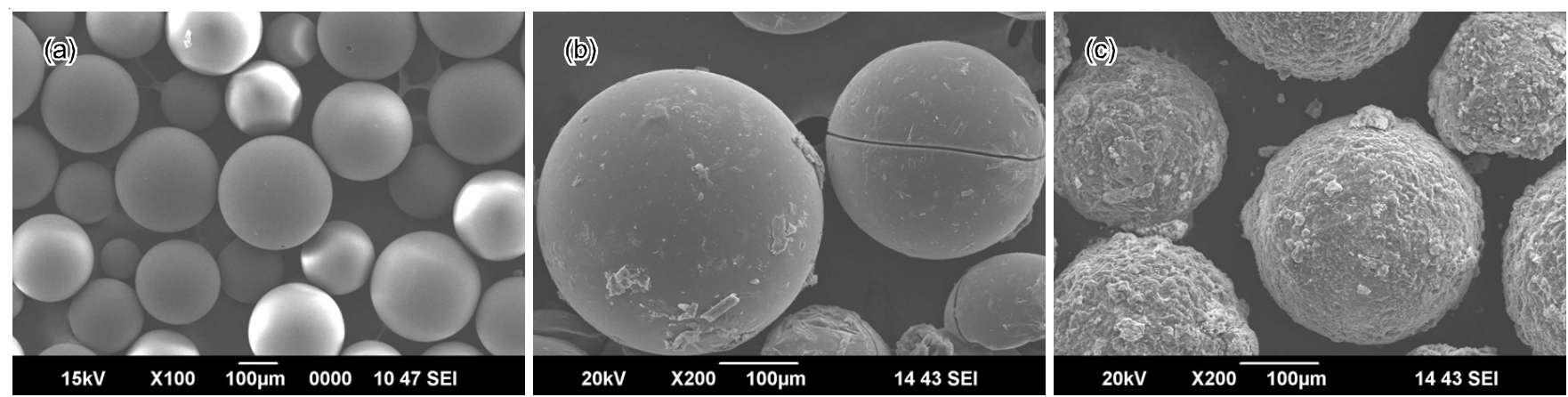

Fig. 4. SEM image of (a) PS-HDODA resin, (b) Sulphonated PS-HDODA resin, (c) Silver nanoparticles loaded sulphonated PS-HDODA resin 

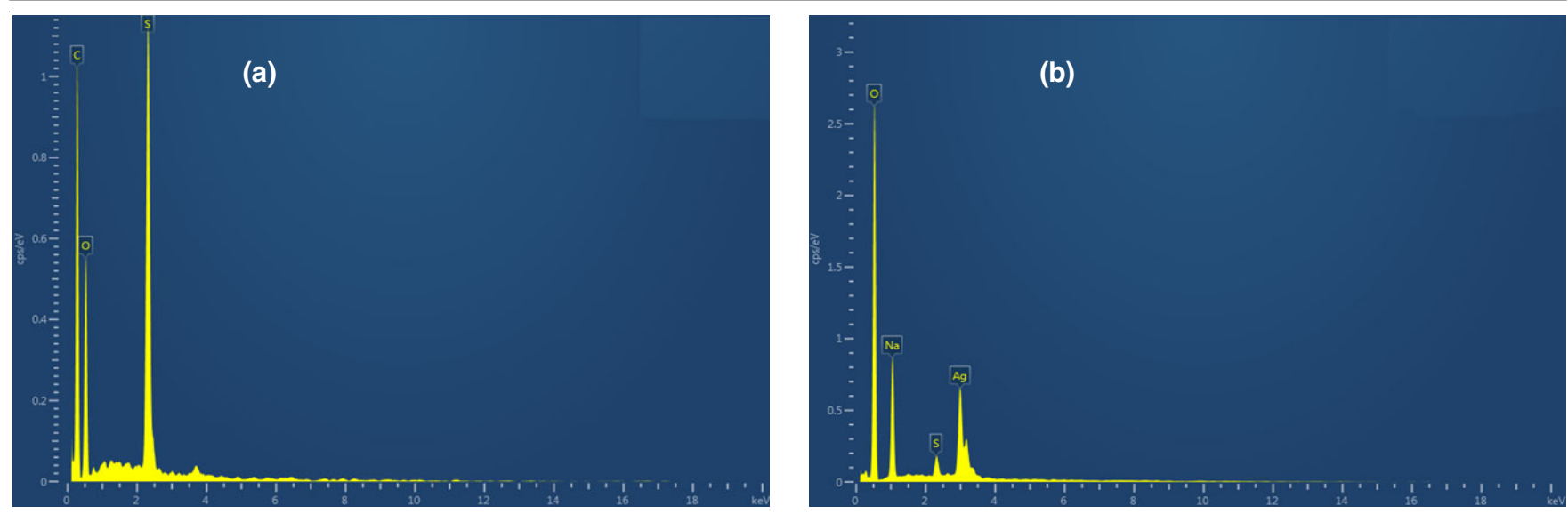

Fig. 5. EDX image of (a) Sulphonated PS-HDODA resin, (b) Silver nanoparticles loaded sulphonated PS-HDODA resin
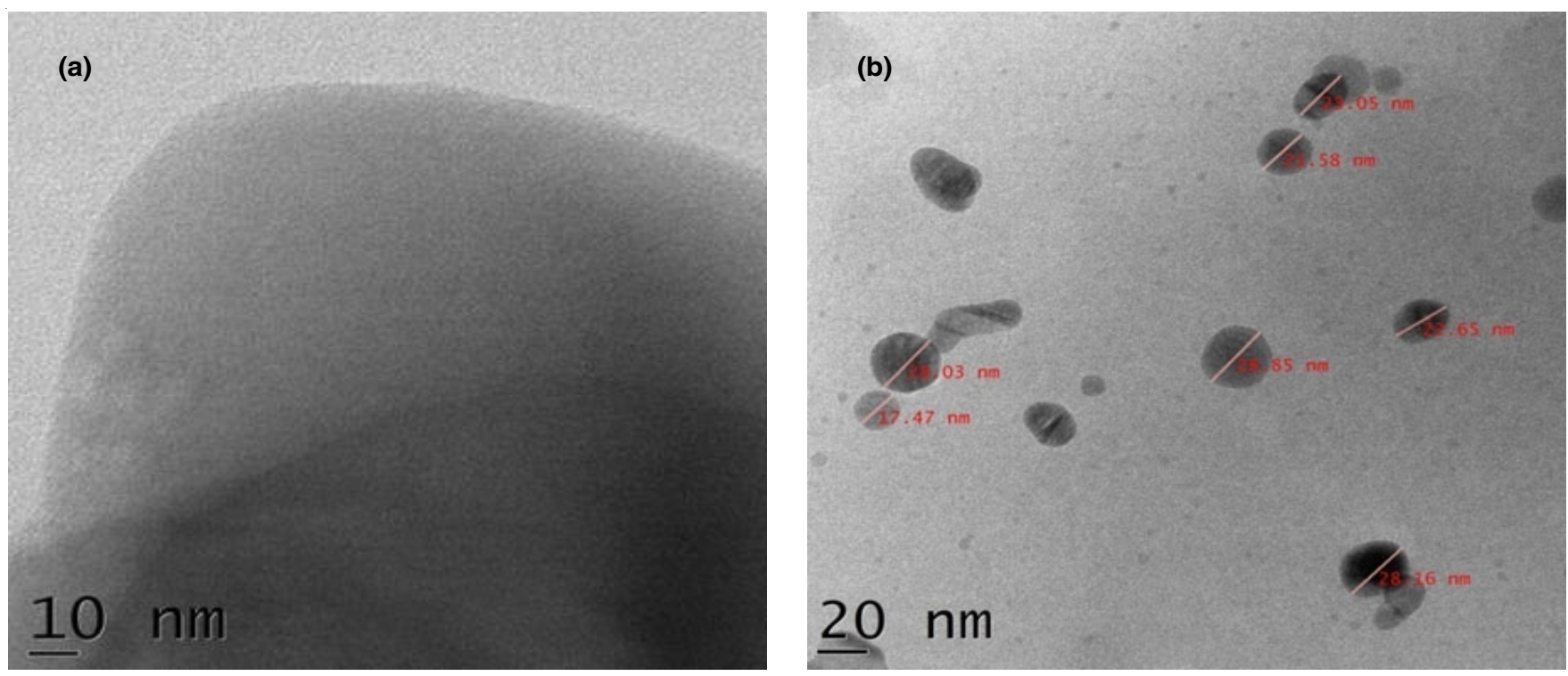

Fig. 6. TEM image of (a) Sulphonated PS-HDODA resin, (b) Silver nanoparticles loaded sulphonated PS-HDODA resin

Elemental analysis X-ray fluorescence analysis: The results obtained are shown in Fig 5. The presence of silver is confirmed by the peaks in the elemental analysis. The peaks for carbon oxygen sulphur sodium have also been observed.

TEM analysis: The TEM image of sulphonated PS-HDODA resin showed very smooth surface (Fig. 6). In metal loaded resin, silver nanoparticles appeared as dark spot inside sulphonated PS-HDODA resin with a size in the range of $\sim 30 \mathrm{~nm}$.

Catalytic activity: Herein, sodium brohydride reduction of $p$-nitrophenol using silver nanoparticles loaded sulphonated PS-HDODA resin was taken as the model reaction. The UV visible spectra for the reduction reaction is shown in Fig. 7. Reduction of $p$-nitrophenol is observed by decreasing absorption peak at $400 \mathrm{~nm}$. The percentage catalytic efficiency was calculated using the following equation:

$$
\text { Efficiency }(\%)=\frac{\mathrm{C}_{\mathrm{o}}-\mathrm{C}}{\mathrm{C}_{\mathrm{o}}} \times 100
$$

where $\mathrm{C}_{\mathrm{o}}$ is the initial absorbance of $p$-nitrophenol and $\mathrm{C}$ is the absorbance of $p$-nitrophenol at time t. From the percentage efficiency plot (Fig. 8) as time increases, the efficiency of catalyst was also increased. From the experimental results, the rate of the reaction corresponds to the first order kinetics (Fig. 9).

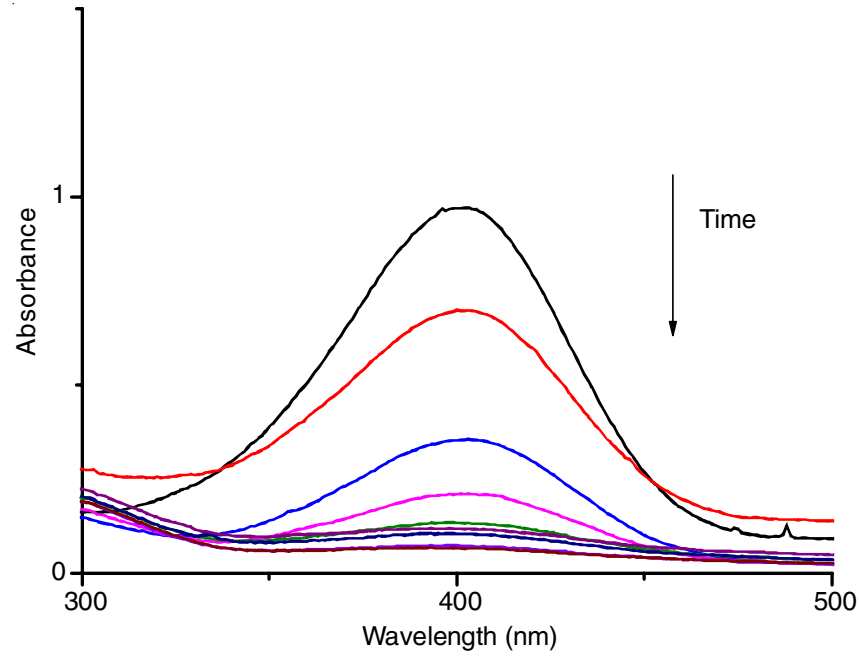

Fig. 7. UV-visible absorbance spectra for catalytic reduction of $p$-nitrophenol

$$
\ln \mathrm{C} / \mathrm{C}_{\mathrm{o}}=-\mathrm{kt}
$$

where $C_{o}$ is the initial absorbance of reaction system, $C$ is the absorbance at time t. From kinetic curve rate, constant $\mathrm{k}$ was calculated for the reaction system. 


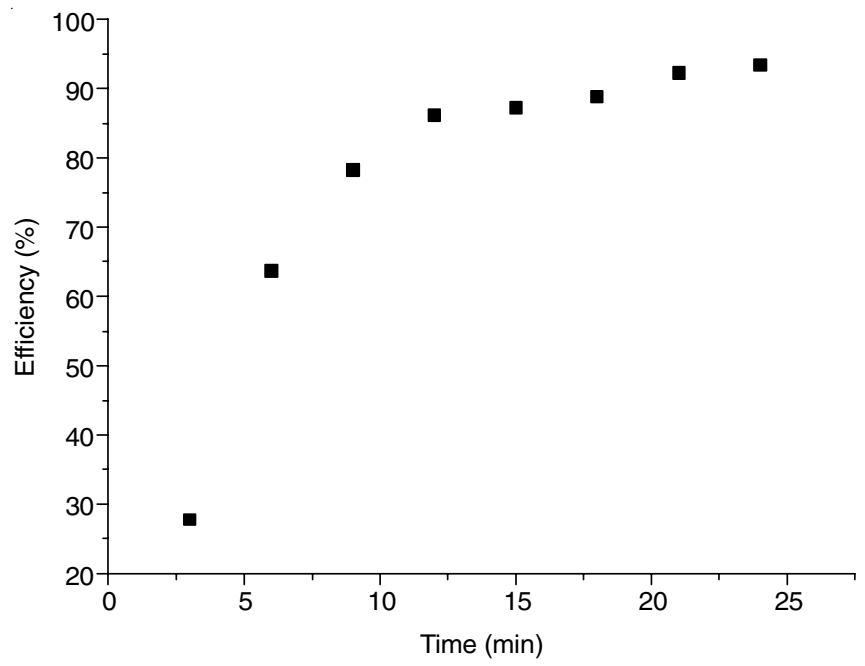

Fig. 8. Efficiency $\%$ with irradiation time for catalytic reduction of $p$-nitrophenol

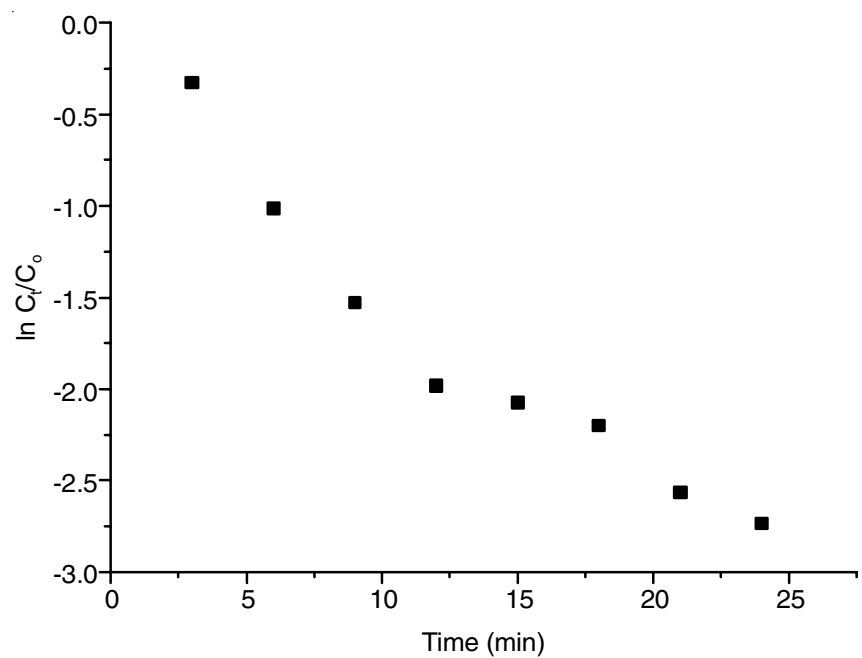

Fig. 9. Kinetic curves for $p$-nitrophenol reduction

\section{Conclusion}

In this study, preparation of silver nanoparticles stabilized in polymeric resin was presented. Suspension polymerization was used to synthesize polymeric 1,6-hexanediol diacrylate (HDODA) cross-linked polystyrene (PS-HDODA) resin. PSHDODA copolymer were converted into polymeric resin by sulphonation of cross-linked polymer. Metal loaded to this polymeric support was converted into nanoscale by sodium boroydride reduction. The catalytic activity of prepared silver nanoparticles stabilized in polymeric resin was tested against $p$-nitrophenol reduction reaction. The catalyst showed $93 \%$ efficiency in the reduction reaction within $24 \mathrm{~min}$. Thus, this catalyst system can be efficiently used for the treatment of wastewater containing $p$-nitrophenol.

\section{ACKNOWLEDGEMENTS}

One of the authors, (JTV) acknowledges the financial support from UGC in the form of Research Award and Anitta Antony is thankful to CSIR, India for the financial assistance. The authors also acknowledge to SAIF, STIC Cochin, India for the spectral and morphological analyses.

\section{CONFLICT OF INTEREST}

The authors declare that there is no conflict of interests regarding the publication of this article.

\section{REFERENCES}

1. G. Schmid, ed.: K.J. Klabunde, In Nanoscale Materials in Chemistry, Wiley-Interscience: New York, pp 15-59 (2001).

2. P.K. Sudeep, B.I. Ipe, K.G. Thomas, M.V. George, S. Barazzouk, S. Hotchandani and P.V. Kamat, Nano Lett., 2, 29 (2002); https://doi.org/10.1021/n1010073w.

3. M. Merschdorf, W. Pfeiffer, A. Thon, S. Voll and G. Gerber, Appl. Phys., A Mater. Sci. Process., 71, 547 (2000); https://doi.org/10.1007/s003390000712.

4. C.-J. Zhong and M.M. Maye, Adv. Mater, 13, 1507 (2001); https://doi.org/10.1002/1521-4095(200110)13:19<1507::AID-ADMA 1507>3.0.CO;2-\#.

5. X.G. Li, S. Takahashi, K. Watanabe, Y. Kikuchi and M. Koishi, Nano Lett., 1, 475 (2001); https://doi.org/10.1021/n1010007u.

6. X. Sun, A. Gutierrez, M.J. Yacaman, X. Dong and S. Jin, Mater. Sci. Eng. A, 286, 157 (2000); https://doi.org/10.1016/S0921-5093(00)00628-6.

7. Y. Kim, R.C. Johnson and J.T. Hupp, Nano Lett., 1, 165 (2001); https://doi.org/10.1021/n10100116.

8. A. Ruiz, J. Arbiol, A. Cirera, A. Cornet and J.R. Morante, Mater. Sci. Eng. C, 19, 105 (2002); https://doi.org/10.1016/S0928-4931(01)00451-9.

9. L. Nicolaisb and G. Carotenuto, Metal-Polymer Nanocomposites, Wiley, Hoboken (2005)

10. S. Baby and K.S. Devaky, Polym. Int., 51, 1411 (2002); https://doi.org/10.1002/pi.1067.

11. P. Thoniyot, M.J. Tan, A.A. Karim, D.J. Young and X.J. Loh, Adv. Sci., 2, 1400010 (2015); https://doi.org/10.1002/advs.201400010.

12. M.R. Maurya, M. Kumar and S. Sikarwar, React. Funct. Polym., 66, 808 (2006); https://doi.org/10.1016/j.reactfunctpolym.2005.11.007.

13. J.P. Ruparelia, A. Chatterjee, S.P. Duttagupta and S. Mukherji, Acta Biomater, 4, 707 (2008); https://doi.org/10.1016/j.actbio.2007.11.006.

14. S. Pandey and S.B. Mishra, Carbohydr. Polym., 113, 525 (2014); https://doi.org/10.1016/j.carbpol.2014.07.047.

15. O.V. Ignatov, O.I. Guliy, I.N. Singirtsev, A.A. Shcherbakov, O.E. Makarov and V.V. Ignatov, Appl. Biochem. Microbiol., 38, 240 (2002); https://doi.org/10.1023/A:1015419307819.

16. H.S. Rosenkranz and G. Klopman, Mutagenesis, 5, 425 (1990); https://doi.org/10.1093/mutage/5.5.425.

17. R.M. Banik, Mayank, R. Prakash and S.N. Upadhyay, Sens. Actuators B Chem., 131, 295 (2008); https://doi.org/10.1016/j.snb.2007.11.022.

18. E. Marais and T. Nyokong, J. Hazard. Mater., 152, 293 (2008); https://doi.org/10.1016/j.jhazmat.2007.06.096.

19. A.O. O'Connor and L.Y.Young, Environ. Toxicol. Chem., 8, 853 (1989); https://doi.org/10.1002/etc.5620081003.

20. M.S. Dieckmann and K.A. Gray, Water Res., 30, 1169 (1996); https://doi.org/10.1016/0043-1354(95)00240-5.

21. L.L. Bo, Y.B. Zhang, X. Quan and B. Zhao, J. Hazard. Mater, 153, 1201 (2008); https://doi.org/10.1016/j.jhazmat.2007.09.082.

22. N. Modirshahla, M.A. Behnajady and S. Mohammadi-Aghdam, J. Hazard. Mater., 154, 778 (2008); https://doi.org/10.1016/j.jhazmat.2007.10.120.

23. P. Canizares, C. Sez, J. Lobato and M.A. Rodrigo, Ind. Eng. Chem. Res., 43, 1944 (2004); https://doi.org/10.1021/ie034025t.

24. S. Mulijani, K. Dahlan and A. Wulanawati, Int. J. Mater. Mechan. Manufact., 2, 36 (2014); https://doi.org/10.7763/IJMMM.2014.V2.95. 